\title{
Roux-en-Y Gastric Bypass and Heller Myotomy: One-Step Surgical Treatment of Symptomatic Achalasia in a Morbid Obese Patient
}

\author{
Nunzio Velotti ${ }^{1}$ (D) $\cdot$ Antonio Vitiello ${ }^{1} \cdot$ Giovanna Berardi $^{1} \cdot$ Mario Musella $^{1}$ \\ Received: 25 January 2021 / Revised: 13 March 2021 / Accepted: 22 March 2021 / Published online: 29 April 2021 \\ (C) The Author(s) 2021
}

Keywords Achalasia $\cdot$ Bariatric surgery $\cdot$ Roux-en-Y gastric bypass $\cdot$ Heller myotomy

\section{Background}

Achalasia is a rare disorder of esophageal motility characterized by the absence of peristalsis and incomplete lower esophageal sphincter (LES) relaxation during swallowing. It usually presents with progressive severe dysphagia and its most effective treatment is surgical disruption of the LES with a Heller myotomy (HM) [1]. Obesity is an independent risk factor for esophageal motility disorders, which may exist in $>50 \%$ of morbidly obese patients [2]. However, obesity is not generally associated with achalasia and the prevalence of this disease in obese patient population varies from 0.5 to $1 \%$ [3]. Bariatric surgery currently represents the best treatment option for morbid obesity and its related diseases and laparoscopic Rouxen-Y gastric bypass (LRYGB) is the second most commonly performed procedure in the world [4]. At same time, HM has demonstrated its superiority over other treatments for achalasia [5]. However, resolution of achalasia symptoms with only laparoscopic HM, expose an obese patient to the risk for further weight gain. Even though the separated management of the two pathologies is well described, current literature lack of consistency about a simultaneous treatment $[6,7]$.

\section{Methods}

Here we present a rare case of a 46-year-old patient with a Body Mass Index (BMI) of $47 \mathrm{~kg} / \mathrm{m} 2$ and an intractable achalasia diagnosed by a high-resolution esophageal manometry (HRMi) and x-rays of upper digestive tract showing aperistalsis and dilation of the esophagus with failure of LES relaxation. Patient had already undergone two endoscopic pneumatic dilations over the 3 years prior to presentation with temporary efficacy.

\section{Results}

He underwent concomitant laparoscopic HM and LRYGB and 6 moths follow-up demonstrated a reduction of BMI to $34,7 \mathrm{~kg} / \mathrm{m} 2$ and the remission of esophageal symptoms. (Figure 1) The patient was classified with an ASA (American Society of Anesthesiologists) score 3 and did not have any previous surgery. Operative time was of 115 minutes and no intraoperative complications were recorded. On post-operative day (POD) 3 the patients started a liquid diet; on POD 5 he was discharged. No early (<30 days) complication occurred.

Nunzio Velotti

nunzio.velotti@gmail.com

1 Department of Advanced Biomedical Sciences, University of Naples "Federico II", Via Pansini n.5, 80131 Naples, Italy 


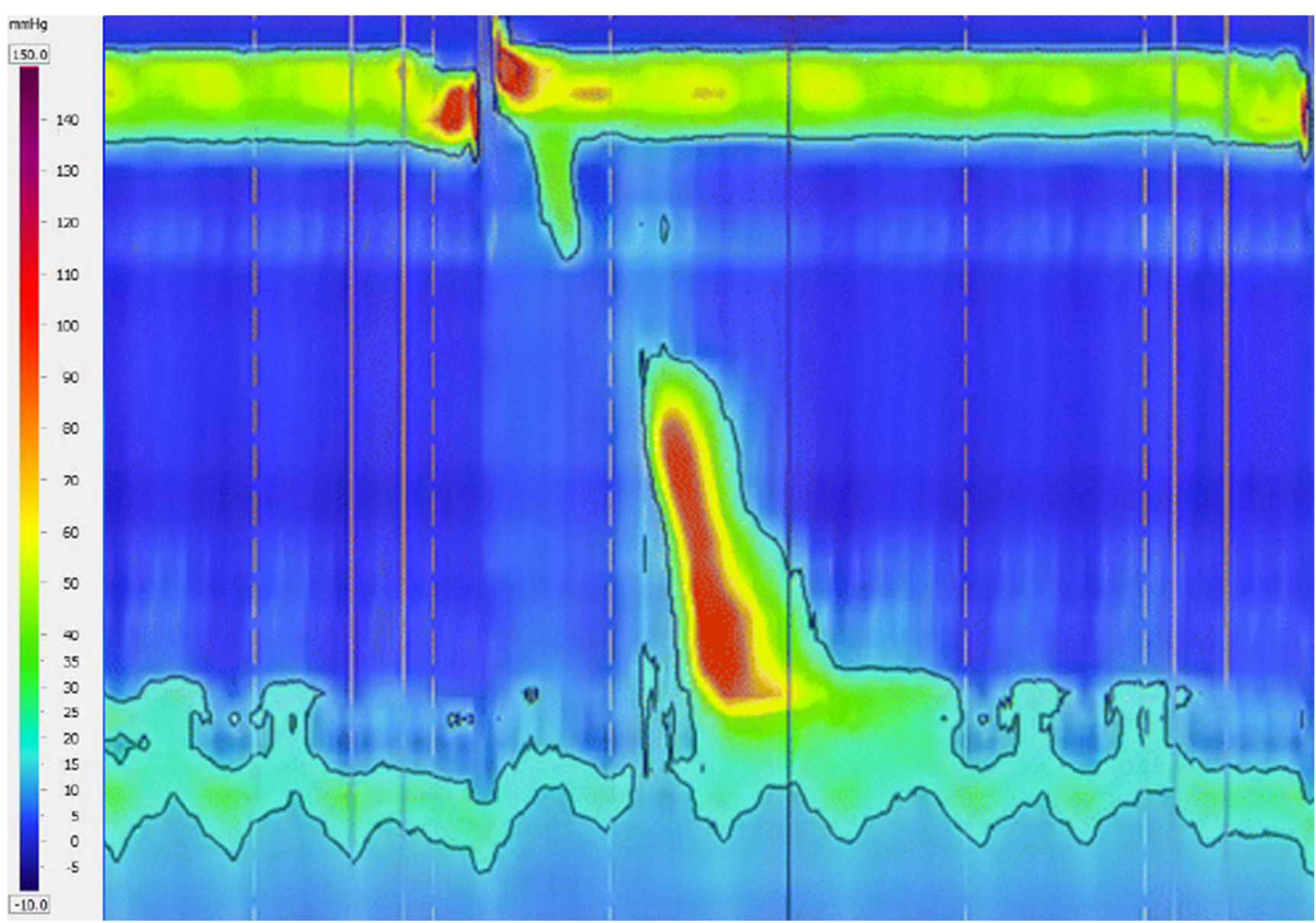

Fig. 1 Six months follow-up high-resolution esophageal manometry (HRMi)

\section{Conclusion}

With the increasing spread of obesity worldwide, the combination of these two diseases may became more frequent and our report suggest thatsimultaneous surgical management of achalasia and obesity with a minimally invasive approach (Heller myotomy and RYGBP) is feasible with successful results for both weight loss and esophageal dysmotility.

Supplementary Information The online version contains supplementary material available at https://doi.org/10.1007/s11695-021-05376-z.

Funding Open access funding provided by Università degli Studi di Napoli Federico II within the CRUI-CARE Agreement.

\section{Declarations}

Ethical approval All procedures performed in studies involving human participants were in accordance with the ethical standards of the institutional research committee and with the 1964 Helsinki declaration and its later amendments or comparable ethical standards.

Informed Consent Informed consent was obtained from all individual participants included in the study.

Conflict of Interest The authors declare no competing interests.

Open Access This article is licensed under a Creative Commons Attribution 4.0 International License, which permits use, sharing, adaptation, distribution and reproduction in any medium or format, as long as you give appropriate credit to the original author(s) and the source, provide a link to the Creative Commons licence, and indicate if changes were made. The images or other third party material in this article are included in the article's Creative Commons licence, unless indicated otherwise in a credit line to the material. If material is not included in the article's Creative Commons licence and your intended use is not permitted by statutory regulation or exceeds the permitted use, you will need to obtain permission directly from the copyright holder. To view a copy of this licence, visit http://creativecommons.org/licenses/by/4.0/. 


\section{References}

1. Pandolfino JE, Kwiatek MA, Nealis T, et al. Achalasia: a new clinically relevant classification by high-resolution manometry. Gastroenterology. 2008;135(5):1526-33.

2. Koppman JS, Poggi L, Szomstein S, et al. Esophageal motility disorders in the morbidly obese population. Surg Endosc. 2007;21(5): $761-4$.

3. Almogy G, Anthone GJ, Crookes PF. Achalasia in the context of morbid obesity: a rare but important association. Obes Surg. 2003;13(6):896-900.

4. Angrisani L, Santonicola A, Iovino P, et al. Bariatric Surgery and Endoluminal Procedures: IFSO Worldwide Survey 2014. Obes Surg. 2017;27(9):2279-89.
5. Oelschlager B, Chang L, Pellegrini CA. Improved outcome after extended gastric myotomy for achalasia. Arch Surg. 2003;138: 490-5.

6. Kaufman JA, Pellegrini CA, Oelschlager BK. Laparoscopic Heller myotomy and Roux-en-Y gastric bypass: a novel operation for the obese patient with achalasia. J Laparoendosc Adv Surg Tech A. 2005;15(4):391-5.

7. Oh HB, Tang SW, Shabbir A. Laparoscopic Heller 's cardiomyotomy and Roux-En-Y gastric bypass for missed achalasia diagnosed after laparoscopic sleeve gastrectomy. Surg Obes Relat Dis. 2014;10(5):1002-4.

Publisher's Note Springer Nature remains neutral with regard to jurisdictional claims in published maps and institutional affiliations. 